dieser Anforderung kann dadurch entsprochen werden, dass das Gefäss von $\mathrm{g}$. bis $\mathrm{c}$ in Cubikcentimeter getheilt wird.

Soll das Gefäss ausgewaschen werden, so bläst man bei a mit der Spritzflasche einige Cubikcentimeter Wasser hinein, schwenkt in horizontaler Lage gut um und lässt das Wasser bei $b$ ausfliessen, diese Manipulation wiederholt man einigemal. ${ }^{1}$ )

Budapest (Museum).

\title{
Abdampftriehter.
}

Von

\section{Dr. S. Bošnjaković.}

In meinem Laboratorium wird bei verschiedenen Bestimmungen der in Figur 2 und 3 abgebildete Abdampftrichter mit Vortheil

Fig. 2.

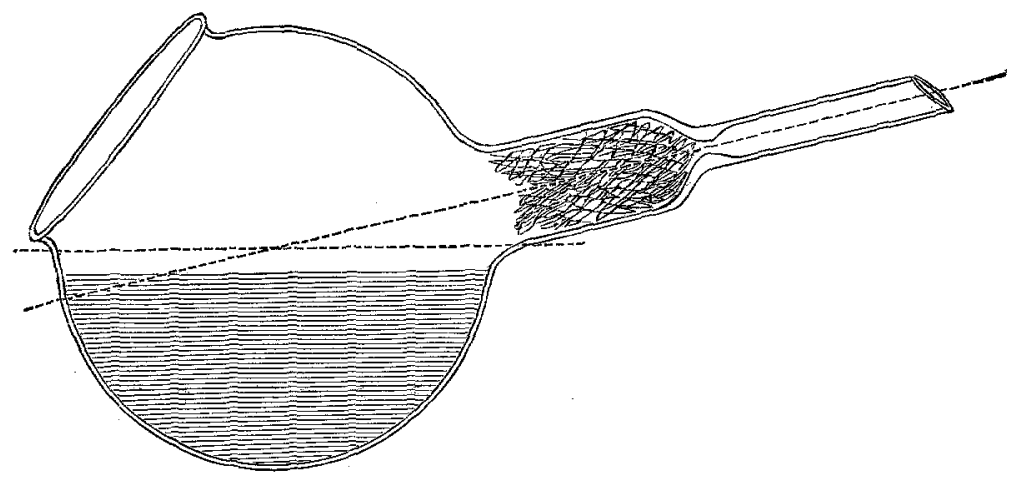

verwendet, und zwar wo man einen direct gefällten Niederschlag oder einen Abdampfrückstand durch Asbest oder Glaswolle za filtriren und zu wägen hat. Es entfällt die oft mit Umständen verbundene Uebertragung des Niederschlages, beziehungsweise Rückstandes, aus einem Gefäss in den Trichter.

1) Dieses Gefäss verfertigt $\mathrm{Nr}$. Karl Kiss ,Glastechnisches Laboratorium“ in Budapest, Esaterházy-Gasse No. 1. 
Fresenius u. Bayerlein: Zur Bestimmung d. Chroms in Chromeisenlegirungen. $3 \mathbf{I}$

Alles Uebrige ist aus den beiden Figuren ersichtlich.

Figur 2 zeigt den Apparat in seiner Verwendung als Abdampfschale, in Figur 3 befindet er sich als Tricher im Gebrauch.

Fig. 3.

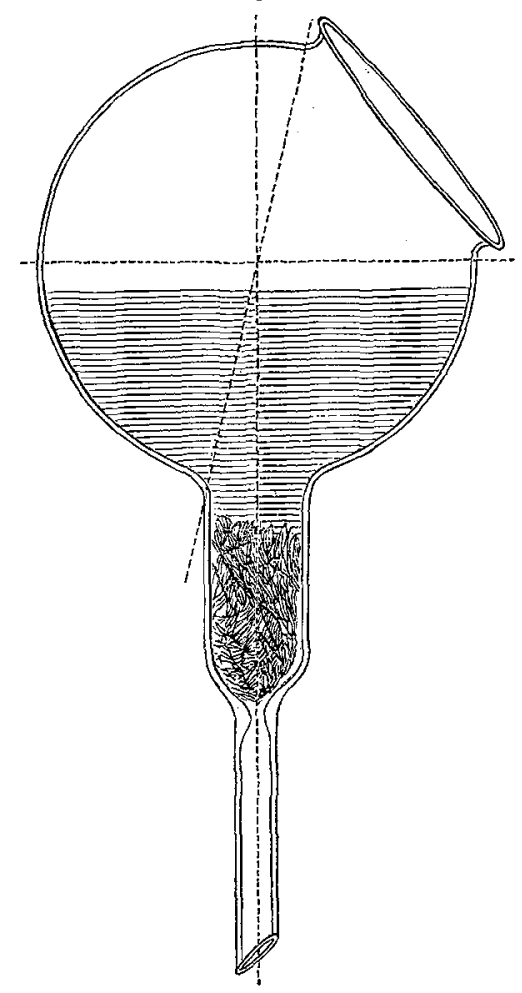

\section{Mittheilungen aus dem chemischen Laboratorium Fresenius zu Wiesbaden.}

Zur Bestimmung des Chroms in Chromeisenlegirungen. Von

H. Fresenius und H. Bayerlein.

Vor einiger Zeit hatten wir in einer Chromeisenlegirung den Gehalt an Chrom quantitativ zu bestimmen. 